\title{
Satisfaction with ophthalmology residency training from the perspective of recent graduates: a cross-sectional study
}

\author{
Tatiana Millán ${ }^{*}$ and Keila Monteiro de Carvalho
}

\begin{abstract}
Background: Few studies have evaluated satisfaction with medical residency programs from the perspective of residents or recent graduates. Knowledge of current conditions of teaching might help to identify deficiencies and to provide adequate training. So, the aim of this study was to assess the satisfaction with residency training and to identify deficiencies in this training from the perspective of recent graduates in ophthalmology residency.

Methods: For this purpose, we developed a questionnaire and gaved it to recent graduates in ophthalmology residency in São Paulo, Brazil, from January to December 2010. The questions contained demographic information (age, sex and time of practice in ophthalmology), a Likert scale to evaluate the level of satisfaction with medical residency concerning clinical knowledge, surgical skills and doctor-patient relationship and questions about deficiency in clinical and surgical areas.

Results: The areas in which recent residency graduates were very or extremely satisfied were: acquisition of clinical knowledge (89.1\%), acquisition of surgical skills (93.4\%) and the development of doctor-patient relationship (74.9\%). Specific areas of clinical knowledge in which they perceived more deficiency were orbit (48.3\%) and ophthalmic pathology (47.9\%), and in surgical skills were refractive surgery (65.9\%) and orbit (59.2\%)

Conclusions: The assessment of the satisfaction with residency training in ophthalmology from the perspective of recent graduates showed high level of satisfaction and identified specific deficiencies in ophthalmic pathology, refractive surgery and orbit.
\end{abstract}

Keywords: Medical education, Medical residency program, Ophthalmology

\section{Background}

The goal of medical residency is the improvement of the medical practice indifferent areas. [1]. The National Committee of Medical Residency that accredits medical residency programs in Brazil established that $80 \%$ to $90 \%$ of the time of medical residency should be developed in the form of in-service training with the theoretical activities in the remaining time [2]. In ophthalmology residency, teaching includes clinic training, acquisition of surgical skills and development of doctor-patient relationship [3].

Several studies have evaluated medical residency in many areas of medicine, such as psychiatry, gastroenterology, neurology, anesthesiology and other specialties. A study in

\footnotetext{
* Correspondence: tatimillan@yahoo.com.br
Department of Ophthalmology, State University of Campinas, Campinas, São

* Correspondence: tatimillan@yahoo.com.br
Department of Ophthalmology, State University of Campinas, Campinas, São Paulo, Brazil
}

(c) 2013 Millán and de Carvalho; licensee BioMed Central Ltd. This is an Open Access article distributed under the terms of the to developing clinical reasoning and diagnostic and therapeutic techniques [4]. Another study examined twenty-six residency training programs in gastroenterology, accredited by National Committee of Medical Residency in Brazil, through open questionnaires to identify the number and the qualifications of preceptors of programs, the frequency of journal club, the number of hours attending outpatient clinics, the access to more complex treatment and the processes of assessment of medical residents [5]. Psychiatry residency training was evaluated through site visits, semi-structured interviews and questionnaires applied to samples of residents and preceptors [6]. Another study evaluated difficulties in patient care and sources of stress during medical residency training [7]. Oliveira-Filho [8] studied the acquisition of knowledge, learning strategies, 
satisfaction with learning environment and quality of life of residents in anesthesiology. None of these studies evaluated the satisfaction with residency training from the perspective of residents.

In ophthalmology we identified some studies in this area. Melo identified the qualifications of ophthalmic educators from a university hospital in Recife, Brazil, using open-ended and closed-ended questioning [9]. In another study that evaluated postgraduate ophthalmic education in the United States of America, 83\% of the doctors who had attended the courses in ophthalmology felt satisfied [10]. Abramoff et al. reviewed the pertinent literature on education in retinal lasers in ophthalmology residency and concluded that there was no standardized curriculum for teaching and assessing resident competencies in retinal lasers [11]. In a systematic literature review, it was suggested the use of a laboratory to teach and assess aspects of resident surgical competence [12]. In another study, specific techniques for teaching and assessing surgical competence in ophthalmology residencies were suggested, such as: written and explicit goals or objectives for each stage of training and the use of formative rather than summative feedback [13]. Golnik et al. developed a 1-page on-call assessment tool (OCAT) and scoring rubric to evaluate ophthalmology resident on-call performance. A retrospective chart audit of consecutive resident on-call charts was performed using the OCAT and they concluded that it could be used to assess resident competence in patient care, professionalism and medical knowledge [14].

The ophthalmology training programs in Brazil are evaluated only by objective parameters such as the number of hours dedicated to outpatient clinic and emergency rooms, the number of surgeries performed by each medical resident, the frequency of lectures and other learning experiences. They are not evaluated from the perspective of residents. Some residency training programs perform theoretical and practical assessments of their residents, but generally the opinions of the residents are not considered. Most studies have been conducted with the objective of assessing the skills acquired by the residents during ophthalmology residency programs using objective parameters, but few studies have evaluated the satisfaction with ophthalmology residency according to the residents' perceptions. Accordingly, the aim of this study was to assess the satisfaction with residency training and to identify deficiencies in this training from the perspective of recent graduates in ophthalmology residency.

\section{Methods/design}

Cross-sectional study.

\section{Survey instrument}

We designed a questionnaire to assess satisfaction with residency training in ophthalmology and to identify deficiencies in the training of clinical and surgical areas. The areas, clinical and surgical, were based on the Mandatory Training Units for accreditation by the Brazilian Council of Ophthalmology, specified in Table 1. Additional file 1: Table S1 shows the applied questionnaire.

\section{Sample}

Inclusion criteria were:

[1] Graduation in an ophthalmology residency in the state of São Paulo, Brazil, accredited by the National Committee of Medical Residency and by the Brazilian Council of Ophthalmology in the last five years;

[2] a 36-month period of residency training.

We opted to study the residents of the state of São Paulo because almost fifty percent of the ophthalmology residents in Brazil have their training in this state, in twenty-six Ophthalmology training programs.

Four hundred and thirty five physicians met these criteria. The true prevalence of ophthalmologists that considered their residency satisfactory in Brazil was unknown because there are no studies that have evaluated this question. Accordingly, a hypothetic proportion of $50 \%$ was assumed for the calculation of the sample size with a $95 \%$ confidence interval. The calculated sample size with a $95 \%$ confidence interval was of 211 subjects.

\section{Statistical analysis}

Pearson's Correlation Coefficient was used to measure the degree of association between the following variables: acquisition of clinical knowledge, acquisition of surgical skills and development of the doctor-patient relationship. The Odds Ratio Chi-Square Test was used to determine whether there was association and the degree of association between perception of deficiency in a specific clinical area and its correlated surgical area.

Table 1 Mandatory training

\begin{tabular}{lc}
\hline Mandatory training & $\begin{array}{c}\text { Percentage of } \\
\text { minimum hours (\%) }\end{array}$ \\
\hline Oculoplastic & 5 \\
Neuro-ophthalmology & 5 \\
Refractive Surgery & 5 \\
Prevention of Blindness and Visual Rehabilitation & 5 \\
Orbit & 5 \\
External Disease/Cornea & 10 \\
Strabismus and Pediatric Ophthalmology & 10 \\
Uveitis & 5 \\
Ophthalmic Pathology & 5 \\
Emergency & 10 \\
Glaucoma & 10 \\
Optics/Refraction and Contact Lenses & 15 \\
Retina & 10 \\
\hline
\end{tabular}


Ethics

This study was approved by the Research Ethics Committee of the Faculty of Medical Sciences of State University of Campinas, SP, Brazil, which was accepted as institutional review board by the Universal Declaration on Bioethics and Human Rights adopted by United Nations Educational Scientific and Cultural Organization.

\section{Results}

Two hundred and eleven recent graduates answered the questionnaire. Ages ranged from 26 to 40 years old: 88 $(41,7 \%)$ were 26 to 30 years old, $113(53.6 \%)$ from 31 to 35 years old and $10(4.7 \%)$ were 36 to 40 years old. Ninety-five (45\%) were men and 116 (55\%) were women.

\section{Overall level of satisfaction}

Table 2 shows the level of satisfaction with medical residency in acquisition of clinical knowledge, acquisition of surgical skills and development of the doctor-patient relationship.

There was a moderate positive correlation between the level of satisfaction with acquisition of clinical knowledge and the level of satisfaction with development of the doctorpatient relationship (Pearson Correlation $\mathrm{r}=0.497, \mathrm{p}<0.001$ ), a weak positive correlation between the level of satisfaction with acquisition of surgical skills and the development of the doctor-patient relationship (Pearson Correlation $\mathrm{r}=0.307, \mathrm{p}<0.001)$ and a weak positive correlation between the level of satisfaction with acquisition of clinical knowledge and with acquisition of surgical skills (Pearson Correlation $\mathrm{r}=0.219, \mathrm{p}=0.001$ ).

\section{Clinical knowledge - specific areas}

Analysis of deficiency in specific areas of clinical knowledge showed that the areas that were perceived as deficient were orbit (48.3\% of the subjects marked it) and ophthalmic pathology (47.9\%). The areas perceived as less deficient were glaucoma $(2.4 \%)$ and ocular emergencies $(4.3 \%)$. Table 3 shows all percentages.

Table 2 Level of satisfaction with medical residency

\begin{tabular}{llll}
\hline & $\begin{array}{l}\text { Clinical } \\
\text { knowledge (\%) }\end{array}$ & $\begin{array}{l}\text { Surgical } \\
\text { skills (\%) }\end{array}$ & $\begin{array}{l}\text { Doctor-patient } \\
\text { relationship (\%) }\end{array}$ \\
\hline Not at all satisfied & $4(1.9 \%)$ & $1(0.5 \%)$ & $3(1.4 \%)$ \\
Slightly satisfied & $3(1.4 \%)$ & $1(0.5 \%)$ & $7(3.3 \%)$ \\
$\begin{array}{l}\text { Moderately } \\
\text { satisfaction }\end{array}$ & $16(7.6 \%)$ & $12(5.7 \%)$ & $43(20.4 \%)$ \\
Very satisfied & $102(48.3 \%)$ & $101(47.9 \%)$ & $89(42.2 \%)$ \\
Extremely satisfied & $86(40.8 \%)$ & $96(45.5 \%)$ & $69(32.7 \%)$ \\
Total & $211(100 \%)$ & $211(100 \%)$ & $211(100 \%)$ \\
\hline
\end{tabular}

Table 3 Deficiency in clinical knowledge areas-overall percentages

\begin{tabular}{lcc}
\hline & No deficiency (\%) & Deficiency (\%) \\
\hline Oculoplastic & 85.3 & 14.7 \\
Neuro-ophthalmology & 75.4 & 24.6 \\
Prevention of blindness and & 68.7 & 31.3 \\
visual rehabilitation & & \\
Orbit & 51.7 & 48.3 \\
External Disease/Cornea & 82.9 & 17.1 \\
Strabismus & 74.9 & 25.1 \\
Pediatric Ophthalmology & 83.4 & 16.6 \\
Uveitis & 94.3 & 5.7 \\
Ophthalmic Pathology & 52.1 & 47.9 \\
Emergency & 95.7 & 4.3 \\
Glaucoma & 97.6 & 2.4 \\
Optics/Refraction & 85.8 & 14.2 \\
Contact Lenses & 89.1 & 10.9 \\
Retina & 89.1 & 10.9 \\
\hline
\end{tabular}

\section{Surgical skills - specific areas}

Analysis of deficiency in surgical skills in each specific ophthalmic surgical areas showed that areas perceived as more deficient were refractive surgery $(65.9 \%$ of the subjects perceived deficiency) and orbit (59.2\%). Areas perceived as less deficient were cataract surgery $(5.7 \%)$, glaucoma $(8.1 \%)$ and ocular trauma (4.3\%). Table 4 shows all percentages.

\section{Correlation areas of clinical knowledge/surgical areas}

The areas correlated were: oculoplastics clinical knowledge/ plastics/ reconstructive surgery, optics/refraction clinical knowledge/refractive surgery, orbit clinical knowledge/ orbit surgery, external disease and cornea clinical knowledge/external disease and corneal surgery, strabismus clinical knowledge/strabismus surgery, emergency clinical knowledge/ocular trauma surgery, glaucoma knowledge/

\section{Table 4 Deficiency in surgical skills by area - overall} percentages

\begin{tabular}{lcc}
\hline & No deficiency (\%) & Deficiency (\%) \\
\hline Plastics/Reconstructive surgery & 75.8 & 24.2 \\
Refractive Surgery & 34.1 & 65.9 \\
Orbit Surgery & 40.8 & 59.2 \\
External Disease/Cornea Surgery & 80.1 & 19.9 \\
Cataract Surgery & 94.3 & 5.7 \\
Strabismus Surgery & 75.8 & 24.2 \\
Ocular Trauma Surgery & 88.6 & 11.4 \\
Glaucoma & 91.9 & 8.1 \\
Retina/Vitreous surgery & 57.8 & 42.2 \\
\hline
\end{tabular}


glaucoma surgery and retina clinical knowledge/retina and vitreous surgery.

Table 5 shows that odds ratio (OR) for perceiving deficiency in some specific surgical area increased significantly when subjects had perceived deficiency in clinical knowledge of correlated area, except for optics and refraction/refractive surgery where the association was not significant.

\section{Discussion}

The results show that the level of satisfaction from the perspective of recent graduates of Ophthalmology residency training was high: $89.1 \%$ were very satisfied or extremely satisfied with the acquisition of clinical knowledge and 93.4\% were very satisfied or extremely satisfied with the acquisition of surgical skills. Only one study [10] has looked at the satisfaction with the post graduation in ophthalmology (83\%), and this showed results similar to ours findings.

We found a moderate positive correlation between the level of satisfaction with acquisition of clinical knowledge and the development of the doctor-patient relationship, and weak positive correlations between the level of satisfaction with acquisition of surgical skills and the development of the doctor-patient relationship, as well as between the level of satisfaction with acquisition of clinical knowledge and the acquisition of surgical skills. This is probably because the subjects that were more satisfied perceived more satisfaction in all aspects.

Despite the satisfaction with the acquisition of clinical knowledge being high, the subjects identified some deficient areas, especially orbit (48.3\%) and ophthalmic pathology $(47.9 \%)$. This is probably because these areas are not traditionally emphasized in ophthalmology residency programs in Brazil, despite the recommendations of the Brazilian Council of Ophthalmology. There are few ophthalmologists in Brazil that have experience in orbit.

In the assessment of surgical skills, analysis showed that the areas that were perceived as more deficient were refractive surgery (65.9\%) and orbit (59.2\%). One possible reason for deficiency in orbit may be that in Brazil, few ophthalmologists perform orbital surgery and that many refer their patients to other professionals, such as oral and maxillofacial surgeons. However, the residency training programs evaluated in this study are the main centers in ophthalmology in Brazil, where the most complex surgeries are performed. That even graduates of these programs would feel deficient in orbital surgery would indicate that surgery should be more emphasized in residency training. In the case of refractive surgery, another perceived area of deficiency, only one residency program in Brazil that was evaluated in this study has training in this type of surgery, even though this is a frequently performed surgery in Brazil. Besides that, the training in refractive surgery is mandatory for the accreditation of residency training programs in Brazil.

Results also show the odds ratio (OR) for perceiving deficiency in some specific surgical area when it had been perceived deficiency in clinical knowledge. Because of the correlation between a specific clinical area and its respective surgical area, when the subjects had perceived that clinical knowledge was deficient, they also had perceived similar deficiency in the surgery. This is an expected result because the acquisition of surgical skills has to be preceded of clinical knowledge, especially in some areas such as oculoplastic (OR: 227.14) and strabismus (OR: 50.56). These are areas where the clinical knowledge is much correlated to the surgery. It just did not happen with the area of optics/refraction and refractive surgery because the teaching of this surgery was inadequate not due to lack of clinical knowledge, but due to lack of infrastructure for teaching this surgery.

We found that the satisfaction with the development of the doctor-patient relationship (74.9\%) was not as high as satisfaction with clinical knowledge and surgical skills possibly because the evaluated residency programs are not working well or are not thorough enough in this area.

\section{Limitations of this type of study}

All data collection instruments which use only the perceptions of the research subjects have high subjectivity, which may reflect more or less accurately the reality.

Table 5 Odds ratio for deficiency in surgical skills according to deficiency in clinical knowledge

\begin{tabular}{lccc}
\hline Area of Clinical Knowledge/Area of Ophthalmic Surgery & $\boldsymbol{p}$ value & OR & $\mathbf{9 5 \%}$ Cl \\
\hline Oculoplastic/Plastics/Reconstructive Surgery & $<0.001^{*}$ & 227.14 & $29.42-1753.3$ \\
Optics and Refraction/Refractive Surgery & 0.25 & 1.84 & $0.75-4.52$ \\
Orbit/Orbit Surgery & $<0.001^{*}$ & 4.7 & $2.58-8.57$ \\
External Disease and Cornea/External Disease and Corneal Surgery & $<0.001^{*}$ & 17.44 & $7.47-40.7$ \\
Strabismus/Strabismus Surgery & $<0.001^{*}$ & 50.56 & 13.04 \\
Emergency/ Ocular Trauma Surgery & $0.001^{*}$ & 13.35 & $20.4-125.33$ \\
Glaucoma/Glaucoma Surgery & $0.003^{*}$ & 39.73 & $1.76-101.2$ \\
Retina/Retina and Vitreous Surgery. & $<0.001^{*}$ & & $5.24-301.34$ \\
\hline OR
\end{tabular}

$O R$ odds ratio, $\mathrm{Cl}$ confidence level, * significant difference. 
Thus, perceptions of graduates may not be the best tool to objectively measure the quality of medical residencies, because at this point, objective examinations performed by Brazilian Council of Ophthalmology would be more appropriate. Nevertheless, the views and perceptions of graduates provide some useful information to assess whether the residency programs are preparing them adequately for the practice from their perspectives. The perceptions of graduates are rarely considered to assess residency programs and, to our knowledge, this is the first study on perceptions of graduates of medical residencies in ophthalmology in Brazil.

\section{Conclusions}

In this study, the satisfaction with residency training in ophthalmology from the perspective of recent graduates in São Paulo, Brazil was high. Despite of that, the graduates identified deficiency specially in the following areas: ophthalmic pathology, orbit and refractive surgery. We should improve training in these areas in the evaluated residency programs.

\section{Additional file}

Additional file 1: Table S1. Questionnaire.

\section{Competing interests}

The authors declare that they have no competing interests.

\section{Authors' contributions}

TM participated in the conception and design of the study, in the acquisition, analysis and interpretation of data and drafted the manuscript. KMM participated in the conception and design of the study, in the analysis and interpretation of data and coordinated and helped to draft the

manuscript. All authors read and approved the final manuscript.

Received: 29 February 2012 Accepted: 23 May 2013

Published: 27 May 2013

\section{References}

1. Brent DA: The residency as a developmental process. J Med Educ 1981, 56:417-422

2. Brazil: National Comittee of Medical Residency, Resolution № 02, May 17, 2006. 2006. http://portal.mec.gov.br/dmdocuments/resolucao02_2006.pdf.

3. Villar MAM, Cardoso MHCA: Medical residence in pediatrics: in the field of practice. Cad Saude Pública 2002, 18(1):329-339.

4. Peçanha AJS: Medical Residency in Gastroenterology: analysis of the role of the Medical Residency in the training of the expert. PhD thesis. Federal University of São Paulo; 1993

5. Calil LC, Contel JOB: A study of psychiatric medicine residency programs in São Paulo, Brazil, in 1993. Rev Bras Psiquiatr 1999, 21(3):139-144.

6. Nogueira-Martins L: Medical Residency: a prospective study on difficulties in the task of care and sources of stress. PhD thesis. Federal University of São Paulo; 1994

7. Oliveira-Filho GR: Acquisition of knowledge, learning strategies, satisfaction with the learning environment and quality of life of residents in anesthesiology. PhD thesis. University of São Paulo; 2006.

8. Lee AG: Graduate medical education in ophthalmology: moving from the apprenticeship model to competency-based education. Arch Ophthalmol 2008, 126(9):1290-1291.

9. Melo MCSC: Educational profile of physicians in a referral hospital in ophthalmic practice: indicator of continuous learning and its use as a fundraiser. PhD thesis. Federal University of São Paulo, Brazil; 2003.
10. Shuttleworth GN, Marsh GW: How effective is undergraduate and postgraduate teaching in ophthalmology? Eye 1997, 11(5):744-750.

11. Abramoff MD, Folk JC, Lee AG, Beaver HA, Boldt HC: Teaching and assessing competency in retinal lasers in ophthalmology residency. Ophthalmic Surg Lasers Imaging 2008, 39(4):270-280.

12. Lee AG, Greenlee E, Oetting TA, Beaver HA, Johnson AT, Boldt HC, Abramoff M, Olson R, Carter K: The lowa ophthalmology wet laboratory curriculum for teaching and assessing cataract surgical competency. Ophthalmology 2007, 114(7):e21-e26.

13. Oetting TA, Lee AG, Beaver HA, Johnson AT, Boldt HC, Olson R, Carter K: Teaching and assessing surgical competency in ophthalmology training programs. Ophthalmic Surg Lasers Imaging 2006, 37(5):384-393.

14. Golnik KC, Lee AG, Carter K: Assessment of ophthalmology resident oncall performance. Ophthalmology 2005, 112(7):1242-1246.

doi:10.1186/1472-6920-13-75

Cite this article as: Millán and de Carvalho: Satisfaction with ophthalmology residency training from the perspective of recent graduates: a cross-sectional study. BMC Medical Education 2013 13:75.

\section{Submit your next manuscript to BioMed Central and take full advantage of:}

- Convenient online submission

- Thorough peer review

- No space constraints or color figure charges

- Immediate publication on acceptance

- Inclusion in PubMed, CAS, Scopus and Google Scholar

- Research which is freely available for redistribution 